MATHEMATICAL ASSOCIATION

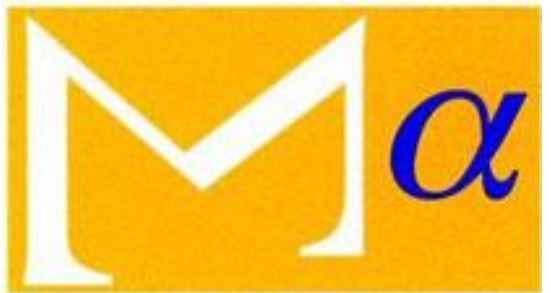

supporting mathematics in education

Review

Author(s): William P. Milne

Review by: William P. Milne

Source: The Mathematical Gazette, Vol. 6, No. 99 (Jul., 1912), p. 348

Published by: Mathematical Association

Stable URL: http://www.jstor.org/stable/3605043

Accessed: 25-02-2016 18:13 UTC

Your use of the JSTOR archive indicates your acceptance of the Terms \& Conditions of Use, available at http://www.jstor.org/page/ info/about/policies/terms.jsp

JSTOR is a not-for-profit service that helps scholars, researchers, and students discover, use, and build upon a wide range of content in a trusted digital archive. We use information technology and tools to increase productivity and facilitate new forms of scholarship. For more information about JSTOR, please contact support@jstor.org. 
The author uses a system of curvilinear coordinates in which the cartesian coordinates $(x, y, z)$ of a point on the quadric

are expressed in the form

$$
\frac{x^{2}}{a^{2}+\lambda}+\frac{y^{2}}{b^{2}+\lambda}+\frac{z^{2}}{c^{2}+\lambda}=1
$$

$$
\begin{array}{cl}
x=\sqrt{a^{2}-b^{2}} & \operatorname{Sn}(u, k) d n\left(v, k^{\prime}\right) c n\left(w, k^{\prime \prime}\right), \\
y=\sqrt{b^{2}-c^{2}} & \operatorname{Sn}\left(v, k^{\prime}\right) d n\left(v, k^{\prime \prime}\right) c n(u, k), \\
z=\sqrt{c^{2}-a^{2}} & \operatorname{Sn}\left(w, k^{\prime \prime}\right) d n(u, k) c n\left(v, k^{\prime}\right), \\
k^{2}=\frac{a^{2}-b^{2}}{a^{2}-c^{2}}, & k^{\prime 2}=\frac{b^{2}-c^{2}}{b^{2}-a^{2}}, \quad k^{\prime \prime 2}=\frac{c^{2}-a^{2}}{c^{2}-b^{2}} .
\end{array}
$$

where out.

The work is highly analytical, Jacobian elliptic functions being used through-

\section{Geometria Descrittiva. By G. Loria.}

The name "Descriptive Geometry" is often used rather loosely, and sometimes confused with Projective Geometry, but in the above treatise it is used exclusively to denote the representation of points in space by points in a plane. In fact, the book applies the methods which the draughtsman uses for his practical problems to the solution of theoretical questions. The work is unlike most English textbooks, inasmuch as the writer does not aim at giving a detailed, manipulative knowledge of the subject, but aims rather at introducing general ideas by applying them to very simple cases. The method of the French mathematician, Monge, receives most attention. Central Projection is explained. In Part I. figures bounded by lines and planes are dealt with ; in Part II. curves; in Part III. surfaces. Only the simplest cases are treated throughout, e.g. polyhedra, surfaces of rotation, the helix and the helicoid, cones and cylindrical surfaces, etc. In this way the student can acquire very clear notions as to loci, envelopes, tangent lines and planes, developable surfaces, without having to learn in the process detailed accounts of the properties of difficult species of such curves and surfaces. There are no sets of examples, most of these being worked out in the text. The work can be thoroughly recommended as an easy and lucid introduction to the notions of higher geometry. It is small in size and not expensive, and the general get-up of the book is quite satisfactory though not equal to that of many English textbooks.

William P. Milne.

Taschenbuch für Mathematiker und Physiker. Pp. 567. 7 mks. 1911. (Teubner.)

This valuable work, which now appears for the second time, contains an immense amount of information; and by the skilful condensation of matters which are to be found in every text-book, room has been provided for a reasonable amount of detail as to many interesting topics which are less frequently handled. Among these a biography of Minkowski (with portrait), twenty pages by Knopf on the determination of cometary orbits, a sketch of the theory of aggregates, a note on integral equations, and a note (ten pages) by Auerbach on the theory of relativity may be mentioned as typical and noteworthy. We hope that the publication will obtain a success proportional to the labour expended on it.

C. S. J.

Sommations par une formule d'Euler. By Enrique Legrañd. Pp. 46. 1911. (Buenos Ayres, Coni Hermanos; and Paris, Gauthier-Villars.)

The formula is the Euler-Maclaurin sum formula, involving the Bernoullian numbers,

$$
\int_{b}^{a} f(x) d x=h \sum_{a}^{b} f(x)-\frac{h}{2}[f(b)+f(a)]-\frac{h^{2} B_{1}}{2 !}\left[f^{\prime}(b)-f^{\prime}(a)\right]-\frac{h^{4} B_{2}}{4 !}\left[f^{\prime \prime \prime}(b)-f^{\prime \prime \prime}(a)\right],
$$

and by means of it the author effects the summation, exactly or approximately, of numerous series, and investigates certain limits, noting incidentally a numerical erratum in Bertrand's Calcul Intégral. A collateral feature of interest is that the text is printed in French and Spanish in parallel columns-the formulae being printed once for all the full width of the page. This is an excellent aid towards picking up a few words of mathematical Spanish.

C. S. J. 